\title{
DIRECTOR'S INTERPRETATION OF KAZAKH DANCE: DEVELOPMENT TRAJECTORIES IN THE PERSPECTIVE OF CREATIVITY
}

\author{
Anipa KUSSANOVA ${ }^{1^{*}}$, Balzhan TLEUBAYEVA ${ }^{2}$, \\ Lyudmila NIKOLAYEVA ${ }^{3}$, Aliya SHANKIBAYEVA ${ }^{4}$ \\ ${ }^{1}$ Department of Choreography, Institute of Social Sciences, Humanities and Art, Kazakh National \\ Women's Teacher Training University, Ayteke bi str. 99, 050000 Almaty, Kazakhstan \\ ${ }^{2}$ Department of Art, Faculty of Culture and Sport, Auezov South Kazakhstan State University, \\ Tauke Khan av. 5, 160012 Shymkent, Kazakhstan \\ ${ }^{3}$ Department of Directing of Choreography, Faculty of Choreography, Kazakh National \\ Academy of Arts, Panfilov str. 127, 050000 Almaty, Kazakhstan \\ ${ }^{4}$ Department of Plastic Stage, Faculty of Theatrical Art, Kazakh National Academy of Arts, \\ Panfilov str. 127, 050000 Almaty, Kazakhstan
}

Received 7 April 2021; accepted 12 August 2021

\begin{abstract}
The study investigates the director's interpretations of Kazakh dance in the perspective of creativity on the example of works dated the last quarter of the 20th - early 21st century to determine the choreography's development vectors with taking into account the aspect of creativity. This research is based on the small and large dance performances analysis. The study relevance lies in the fact that it can become a tool for determining the expression level of the national aspect in Kazakh dance art. The results of the study show the role of creativity in the dance education and its effectiveness in the development of Kazakh dance art. This tool is necessary for the choreographer's worldview theoretical analysis and his/her dance interpretation, for the Kazakh choreography subsequent enrichment, and preservation of Kazakh historical identity.
\end{abstract}

Keywords: choreographic art, creativity, dance directing, dance interpretation, Kazakh dance, stylistic features.

\section{Introduction}

A significant role in the development of modern dance art is played by creativity, which makes it possible to distinguish one culture from another by dance traditions. Creativity as one of the leading professional competencies makes it possible to create new creative ideas and implement them in the form of dance through a system of movements (Chappell \& Hathaway, 2018). Based on this, the concepts of dance and creativity are closely linked, as dance,

*Corresponding author. E-mail: anipa.kuss@rambler.ru

Copyright (c) 2021 The Author(s). Published by Vilnius Gediminas Technical University

This is an Open Access article distributed under the terms of the Creative Commons Attribution License (http://creativecommons. org/licenses/by/4.0/), which permits unrestricted use, distribution, and reproduction in any medium, provided the original author and source are credited. 
created on the principle of creativity, makes it relevant, original and non-traditional (Łucznik \& May, 2021). It is considered that creativity increases openness and confidence, allows the art of dance to move to a new stage of development by updating methodological approaches, expanding dance opportunities in movement and music (Clements \& Redding, 2020). In addition, creativity provides an opportunity to look at the history of dance in a different way and update it by adding modern methods and increasing efficiency, without changing the essential understanding of the dance tradition (Kasirer \& Shnitzer-Meirovich, 2021).

The traditional culture of an ethnic group cannot be perceived fully without its history (Banban, 2018; Ma, 2007). From this perspective, dance is perceived as an integral part of any nation (Nasev, 2013). As a syncretic form of art, Kazakh dance underwent a long and challenging development path from movements captured in cave paintings to virtuoso dances. It was repeatedly distorted in perception or performance due to the lack of grounded information on its essence and technique. Despite the traditional nature of modern Kazakh dance is characterized by creativity in the improvisational structure and its basic movements.

Kazakh dance culture was born in unity not only with the rhythm and melody of folk music, but also with arts and crafts, oral poetry, language, rituals, and traditions (Malloch \& Trevarthen, 2018). Each movement in Kazakh dance has its own meaning. Considering this, when creating a choreographic image, director-choreographer must select dance vocabulary (dance movements) and synthesize it according to the dance context and accents set within the performance based on the aspect of creativity and its main characteristics (Carey et al., 2019). The close interaction of the dance context and chosen accents is defined by researchers as choreographic integrity (Stinson, 2006).

Like any art, choreography lives for the sake of the content, which can be expressed only after creating its material form (for example a dance performance) (Karp, 1980; Pavlik \& Nordin-Bates, 2016). In a similar vein, it is noted that in any form of art, a visual image is fragmentary (Hanakawa, 2016). Therefore, the integrity of choreography, in general, should be expressed both at the level of semantics and plastique (Guss-West \& Wulf, 2016). Thus at creation of all components of dance it is necessary to consider creativity, after all in each movement of the executor something original and unconventional should be traced to attract attention of the spectator and to interest him with all performance.

Choreographing a dance performance according to his/her vision, the director, must not only be able to achieve the concurrency of movements and provide a perception of the dance as a whole but also take into account the creative component of his professional competencies (Coulson-Thomas, 2017).

Summarizing the thoughts of researchers in the field of choreography, one can draw a conclusion that the activity of a director-choreographer is aimed at achieving harmony and consistency of all components based on the principles of creativity. This assumption suggests that the activity of the director-choreographer is focused on creating an artistic image by adding the corresponding expressive movements of the human body, musical content, compositional construction, lighting, costumes, and emotions creating something new onoriginal and non-traditional with the help of creativity. In their unity and integrity, these aspects effectively represent dance director's world outlook and are the main ways to display unique features in a dance performance (Carter, 2020). 
Since ancient times, the original culture of the Kazakh people was influenced by numerous socio-historical factors and based on the connection of ancient tradition and contemporary creativity. An in-depth analysis of scientific literature allowed generalizing Kazakh choreography's achievements in the period from the 1970s of the 20th century to the beginning of the 21st century (Zhanibek et al., 2020). Besides, it gave an opportunity to characterize the main stages of Kazakh choreography development in the perspective of creativity, identify its most significant challenges, and outline its future prospects. The present research was aimed at revealing and analyzing the directors' interpretations of Kazakh dance in the perspective of creativity. The fulfilment of the study objective presupposed the solution of the following tasks:

- Analyze the aspect of creativity, its role and effectiveness, in the creation and functioning of Kazakh dance;

- Unveil the methodological framework for the analysis of the director's interpretation of the dance;

- Reveal the specifics of the director's interpretation of the Kazakh dance in the perspective of creativity on the examples of dance performances of the last quarter of the 20th century and determine its significance for the history of Kazakh choreography;

- Analyze the development of "creative aspect" of Kazakh directors-choreographers on the example of dance performances of the beginning of the 21st century;

- Formulate the goals for the further development of choreography.

\section{Materials and methods}

Many research works in the field of Kazakh choreographic art have considered issues related to the development of Kazakh national dance from the perspective of directing based on the creativity aspect. Nevertheless, they do not contain any relevant information on the topic under consideration.

This research provided a comparative analysis of the development of the director's interpretation of Kazakh dance in the perspective of creativity based on the performances of the late 20th - early 21 st century. The study investigated dance directing experience, represented by the names of Zaurbek Raibayev (ballet Frescoes (established in 1981) and dance performances Sholpy (in English: pendants) (established in 1989) and Asatayak (established in 1984)), Mintai Tleubayev (ballet Aksak Kulan (established in 1975)), Gulnara Adamova (ballet Zheztyrnak (established in 2005)), Aigul Tati (dance routines Arular (established in 2012) and Asem Konyr (established in 2014)), and Anvara Sadykova (ballet Turan dala Kyran dala (established in 2017)).

The examination of the Kazakh choreography in the perspective of creativity was predominantly based on archaeological data and cave paintings depicting scenes that resemble the dance of an ancient man, as well as the considerable body of literature. The use of various literature sources in combination with other materials allowed systematizing the available knowledge taking into account the creativity aspect and its role in the creation of dance, gave a more precise understanding of Kazakhstan ballet art as a visual phenomenon, and enabled the use of interdisciplinary research methods when studying the history of choreography. In preparing the article, various scientific works with descriptions of dance performances (both 
published and archived) and museum exhibits and materials (photographic documents, video recordings) were used. What is more, historical, cultural, contextual, and typological methods, as well as the method of theatrical and artistic analysis, were applied.

The research materials will be of practical use in teaching choreography, as they can notably enrich the theoretical base of a number of major disciplines in the field of ballet studies, directing, and dance pedagogy in the perspective of creativity.

\section{Results}

The analysis of the works of Raibayev, Tleubayev, Adamova, Tati, and Sadykova show that they are based on the creativity that has the great effectiveness in the creation and functioning of their choreography. It is determined that taken into account aspect of creativity make their dance more original and non-traditional.

The performance choreographed by Tleubayev, music to which was written by Almas Serkebayev was based on the legend about Aksak Kulan. This composition is characterized by a tendency to refer to well-known folk traditions, legends, and poems. At the same time it is created on the principles of creativity as well as the director not copies the legend but makes its interpretation based on his own view of its plot and main idea taking into account modern creative methodology of dance.

The innovative ballet Frescoes, choreographed by Raibayev to the music of Timur Mynbayev, marks the beginning of the 1980s and is based on creative interpretation of historical event. It should be noted that before the creation of Frescoes, the chronology of ballet topics used to start from the period of the formation of the Kazakh Khanate. However, Raibayev refers to an even earlier period of the ethnogenesis of the Kazakh people. According to the history, calculated from the period of the Bronze and Iron Ages, numerous tribes of the Turkic ethnos (Sakas, Wusun, Kangju, Huns) lived on the territory of modern Kazakhstan. This provoked their cultural heritage to become a part of the basic culture of the Kazakhs and resulted in the direct impact on the Kazakh dance vocabulary.

The creation of dance is realized with the help of the director's stylization methods, which represent a synthesis of classical and modern dancing techniques and consider the director's appeal to creativity. In combination with finger movements, the unique movements of hands reveal the ultimate message of the dance. The manifestation of this is already observed in the first scene called Kurgan stelae. A dance performed by priestesses in the temple of the goddess Ishtar, accompanied by movements of fingers with palms turned upward and varieties of hand positions syilyk (in English: gift), expresses worship and the process of giving offerings to the Sun. The director's compositional construction methods, sometimes expressed in the form of a circle, personifying the shape of the Sun, successfully convey the idea of this scene presented in a creative non-traditional interpretation.

In the threshold of new trends in its development, dance art turns to the ritual basis, in the depths of which it was born. Just as the foreign practice of getting back to the roots, vividly represented in the works of Ruth St. Denis, Vaslav Nijinsky, or Maurice Béjart, Raibayev's activity contributed to the search for ways to create new tendencies in the national dance interpretation. 
The ballet Frescoes, distinguished by its thematic content, immerses the viewer into a more distant history period than previously choreographed dance performances. It revives the formation of Kazakh ethnogenesis, at the same time the director proposes new point of view according to the aspect of creativity.

Considering Raibayev's interpretations in the context of traditions and innovations, one can notice that his idea of creating a dance performance with the modern implementation of archaic themes, determines the importance an unusual, innovative decision-making ability of the choreographer. It is considered that this work represents the connection of tradition and creativity. This gives the right to think of Raibayev as an innovator and a pioneer on the path of modernization of artistic thinking in the context of creative understanding of dance art. Raibayev's principles and techniques in creating a holistic choreographic work turned out to be an effective means of interaction between the past and present, tradition and creativity. His director's interpretation of the Kazakh dance in the Frescoes became the starting point for the formation of creative aspect of young directors-choreographers in the process of the interpretation of traditional Kazakh dance. This creative aspect, as well as most of the steps in the formation of modern Kazakh choreography, took place in the mainstream of similar decisions of Western transcending pedagogical theory and stage practice (Moldakhmetova et al., 2018). In particular, dance choreography and the creative spontaneity characteristic of folk dance are used for early training in choreography by a number of contemporary studies (Rudd et al., 2021).

Along with the creation of the Frescoes, the name of Raibayev is connected with a number of fantastic theatre dances that have become treasures of the choreographic heritage of Kazakh people. Over the years of creative activity in the state dance ensemble Saltanat (established in 1955), Raibayev choreographed such dance performances as Asatayak, Kos-Alka (established in 1984), Sholpy, Bishi Kayyn (in English: dancing birches) (established in 1989), Kazakh Rhapsody (established in 1990), and others.

The name of the dance Asatayak comes from the name of the ritual noise-producing instrument in the form of a rod, covered with metal suspensions, which is widely used by shaman in their healing rites (Mukhambetova, 2003). Raibayev choreographed the dance Asatayak to the composition of Nurgisa Tlendiyev Ata Tolgauy (established in 1962). This choice fully meets the idea of the creation of Asatayak on the basis of new creative interpretation of the previous variant. The title Ata Tolgauy can be loosely translated as "thoughts of ancestors". The word tolgauy has a philosophical and didactic meaning and meets the choreographer's aspirations to materialize a holistic image and express the richness of the Kazakh culture.

Raibayev's interpretation of the Kazakh choreography is widely known for its frequent references to the culture of Kazakhstan, particularly, to folk applied art. This fact can be proved by the dances Kos-Alka (to the music of Dauletkerey Shygayuly) and Sholpy (to the music of Serik Yerkimbekov).

Dance Sholpy choreographed by Raibayev together with the Saltanat represents the creative interpretation of previous variants of dance traditions. The choreographer's idea of revealing and conveying the sacred protective function of the sholpy finds its embodiment in the dance vocabulary, stage image, intertwined positions of hands, which reinforced the sound of sholpy and protected women from evil spirits. Along with this, Raibayev indirectly 
transmits additional information about the features of traditional education. In particular, an unmarried girl was forbidden to be in the wrong place - the sound of sholpy could betray her presence. The significance of the director's interpretation of this dance lies in the fact that it acts as the personification of the cultural traditions of the Kazakhs. It expresses the ancient etiquette, reflects the aesthetic views of people, and uncovers some aspects of traditional education, at same time all these aspects are based on the concept of creativity as well as the director represents own interpretation of ancient dance.

Another piece of the fascinating legacy of the director-choreographer Raibayev is a dance Bishi Kayyn set to the music of Kenzhebek Kumisbekov. The analysis of this composition shows that it represents the skilful ability of the choreographer to achieve contextual and intonational expression by means of an appropriate selection and precise combination of Kazakh dance movements. Raibayev artistically conveys images of swaying branches, their shaking branches, as well as strong bends under the influence of the wind. The performers of this dance seem to be a real personification of dancing birches that indicates the director's appeal to creativity.

Continuing the research and analysis of the director's interpretation of Kazakh choreography, it should be noted that Kazakh artists were primarily focused on reviving the traditional forms of Kazakh culture with the actualization of the principles of creativity in the dance formation. This was facilitated by the formation of the folklore-ethnographic ensemble Altynay. The creation of Altynay ensemble served as a prerequisite for the implementation of a vast repertoire of Kazakh folk dances, most of which today make up the golden fund of the choreographic heritage of Kazakh choreography.

The analysis of the creativity of directors-choreographers of the second half of the 20th century revealed heightened attention to the preservation and revitalisation of elements of culture with the help of creativity and its main aspects. The creation and development of the repertoire of a number of dance ensembles were based primarily on folk culture. During this period, directors-choreographers created many pieces of national choreography that provided an authentic representation of Kazakh ethnography and traditions.

The great merit of Kazakh choreographers of the late 20th century lies in the revival of the culture in dance and its creative updates at all levels. Therefore, the semiotic code embedded in dance routines is important in creating a kind of guarantor of the transmission of the national context from generation to generation. The creativity of the directors and choreographers of that time gained a creative and original interpretation of the work of our contemporaries. The images taken from Kazakh mythology were manifested in a completely different creative way. Directors-choreographers Adamova, Tati, and Sadykova, referring to the national themes of the past, focus on the philosophical interpretation of the world events and eternal questions about human essence. Their dance performances may serve as an example for subsequent references to the genre of fairy tales or mythology, through which one can provide insight into other relevant topics.

Choreographers have different approaches to solving the problem of the creativity and originality of choreography and, accordingly, its development. Being in an intense and contradictory search, they independently develop the principles of understanding dance art and criteria for using folk dance elements according to modern creative methodology of 
dance. This leads choreographers to the creative and original interpretation of folklore images (Shankibayeva, 2011).

The study of Tati's interpretation of Kazakh choreography is based on the period of her directing in the Astana Ballet, Kazakhstan collective and teaching in the Kazakh National Academy of Choreography, Kazakhstan. During Tati's creative activity in the Astana Ballet, she directed such dances as Shattyk (established in 2012), Arular, Assem Konyr, Nur shashu (established in 2013), Ornekter (established in 2014), Kerbez (established in 2015), Syi-Siyapat (in English: souvenirs) (established in 2016). Out of the remarkable performances mentioned, the Astana Ballet hallmark is the Arular dance, premiered in 2012. To some extent, Arular is close to round dances as it presents a procession of boyjetken (in English: girls-brides). As for the structure of the choreographic text, Tati attaches great importance to hands. In one of her many interviews, she stated that hands are an expression of our soul. Tati skilfully conveys the beauty of a girl's personality through a careful choice of movements combined semantically and plastically.

Tati's interpretation of dance Asem Konyr (Figure 1) is especially admirable as well as it is based on the basis of non-traditional interpretive model in accordance with the principles of creativity. It is completely different from Arular. Even though this dance performance reveals a warlike character of Kazakh woman, it is distinguished by tender movements. Another peculiarity of this interpretation is a three-act narrative structure that consists of an introduction, where the viewer smoothly immerses in the steppe history, a slow lyrical climax and an energetic coda.

The choreographic text of Asem Konyr consists of traditional Kazakh dance movements, with the main emphasis on port de bras. The poetic images of the surrounding reality are manifested through the kos kol (in English: parallel arms) position. Tati's interpretation of

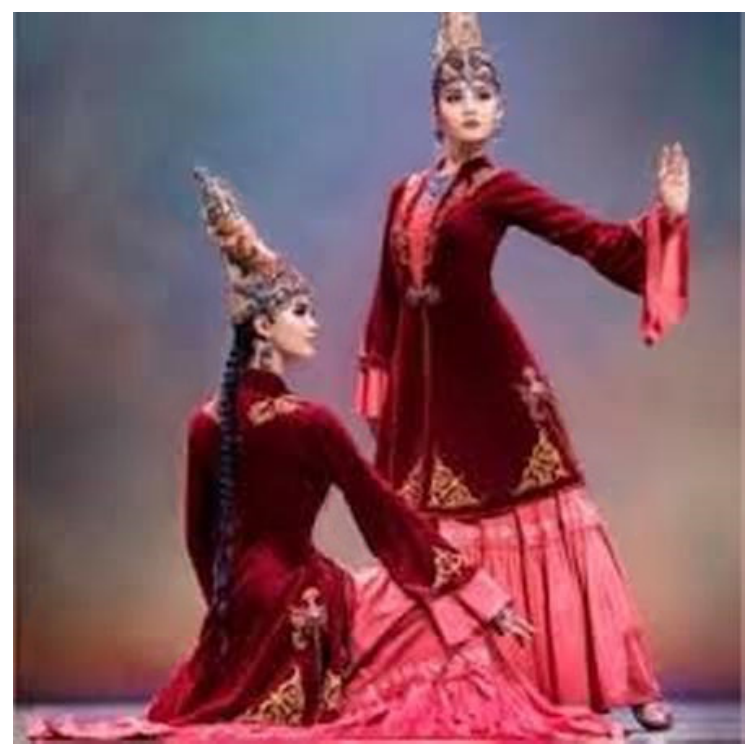

Figure 1. Dance Asem Konyr (2014) (source: created by authors) 
aesthetics of stamina, tolerance, and the warlike character of a Kazakh woman amazes. The frequently met fourth position in one hand and the precise horizontal movement of the second convey the image of a strong spirit of Kazakhs, full of inner dignity and nobility.

In the second part of the dance composition, the performers, gathering in the back of the stage and holding their hands in the ulken syilyk (in English: a big offering) position, line up tightly, representing a "staircase". Gradually rising from their knees, the girls personify the process of worshipping their native land, preserving its natural and spiritual wealth, and carefully transferring this beauty to future generations. This image is a vivid expression of the unity of music and lyrics in a dance performance.

In the code, the choreography is characterized with movements of wide amplitude. The movement of hands shyntak tolyn (in English: elbow waves) conveys the image of waves of a stormy mountain river. It accompanies the dynamic movement of performers from the centre to different parts of the scene. Tati's interpretation of Kazakh dance is characterized by the increasing complexity of dance vocabulary that contributes to the masterful representation of the illustrative and poetic nature of the musical work. On the other hand, the main emphasis she puts on the preservation of national identity and traditions.

The investigation of the interpretation of Kazakh dance of the present time period is represented by the ballet show Turan dala - Kyran dala. It was choreographed by Sadykova to the music of the folklore and ethnographic ensemble Turan and Kazakh composers Shygayuly, Tlendiev, Aigul Mukey, and Aktota Raimkulova. The ballet begins with the ritual actions of the shaman baksy who performs his dance accompanied by the sounds of a percussion instrument. This simple melody brings life to figures from cave paintings that stand in various poses with specific hand positions bes sausak (in English: five fingers), jogary-tomen (in English: up and down), sharshy (in English: square), and syilyk (in English: offering). The images of these figures, creating an atmosphere of antiquity, contribute to the immersion of the viewer in the ancient time.

The ballet continues with the picture of zhoktau (in English: a song of lamentation). Here, with the help of the dance language, Sadykova tried to convey the sorrow of the death of birds, which used to personify peace and purity of deeds and thoughts. The choreographic text is represented by the traditional movements of Kazakh dance, intertwined with elements of contemporary choreography. A characteristic feature of this scene is the presence of a specific fragmentation of dance figure movements, which allows the viewer to distinguish elements that express various emotions. Performers' costumes also contribute to the expression of loss and despair. However, their one more important role is in rendering the idea of national identity through the embroidered ornaments and accessories, the absence of which would make the costume just a reflection of some pagan clothing.

In general, Turan dala - Kyran dala presents a metaphorical story about the history of the Kazakh people that indicates the director's appeal to modern creativity. Here, the absence of attachment to a specific plot and the desire to embrace an extensive time period bears a representative character. In this regard, the fragmentation of the musical material, collected from the works of different composers, contributed to the inclination of each specific action to a separate dance number (petroglyph dance, shaman dance, Tengri and Umai dances, dance of swans, dance of mourners). 


\section{Discussion}

The results of the study based on the analysis of directors' interpretation of national dance traditions in the perspective of creativity show that while creating national dance performance, the composition of its choreographic text is of foremost importance. The choreographic text consists of dance vocabulary, movements, and postures and is believed to be the main way to show the expression of the performance based on the principles of creativity. Both in theatre dance and ballet, choreographic text is built according to the theme, concept, and idea of future work. It should be remarked that the specificity of the ballet performance, characterized by the presence of finger technique, presupposes a simplification, and sometimes even completely impossible use of folk dance moves, which cannot be said about the theatre dance itself (Powell, 2019). The conception of modern dance is being transformed into freer forms of expression and spontaneity, in which ethnic elements acquire a natural and even predominant position as a means of increased expressiveness (Powell, 2019). Theatre dance may combine national aspects with the directions of choreography on pointe. Consequently, its choreographic text is formed according to the choice and vision of the director and is manifested in various choreographic forms, which are examined in detail by Sytova (2001). Director's interpretation of dance, according to Sytova, is conducted in the following three ways:

- Adaptation;

- Creation of a new dance based on traditional choreographic techniques, elements, plastique and performance manner;

- Application of the most general stylistic features of the original source while creating a modern choreographic performance (Sytova, 2001).

Ways of interpreting the dance proposed by Sytova describe general, well-known patterns. Shumilova (1974) has covered the development of choreographic forms of dance interpretation in the form of the ladder, clearly representing the methods of combining different dance languages when building movements. The first step of her ladder is a traditional dance with all the attributes of ethnography. A little higher is the adapted dance, which has absorbed only the basics of the traditional culture. Here, elements of theatricality, a complicated composition, enriched dance vocabulary, as well as stylized costumes, can appear. Then the choreography combines (sometimes mechanically) the foundations of academism with the application of national movements: the legs perform a pas of classical ballet, while the national plastique is seen in the hands' movements. The next step is the synthesis of two principles - the plastique of traditional academic dance (ballet) with the plastique of national choreography. The same approach was formed during the second half of the 20th century in the French, American and British national choreographic schools (Carter, 2020). At the very top of this imaginary ladder, Shumilova (1974) sets choreography, which contains minimum national components, but seeks to convey the values of a specific culture. The above-noted steps represent variants of choreographic form-making, used in both small and large dance performances. However, in order to clearly define and apply them in work, they require more thorough consideration.

Being an indispensable part of folk culture, the traditional dance bears elements of a cultural tradition and heritage and passes them down from generation to generation. Therefore, 
it contributes substantially to the reinforcement of cultural identity and plays a crucial role in the "cultural development" of society. Today, the culture of any nation is going through a constant process of mutation. Some traditional elements get lost, while others resist and survive or get transformed and readjust to new emerging circumstances (Georgios, 2018).

The unique charm of national dance lies precisely in its cultural value. Traditional dance absorbs the essence of national culture. It is both vivid and rich, and it is not only part of the culture itself but also depicts its character (Wang \& Zhang, 2018). The activation of ethnic cultures, the search for self-preservation and their further qualitative development under the conditions of coexistence and cooperation are the requirements for the development and formation of national identity, strengthening the multinationality and versatility of folk art, and the embodiment of national culture in contemporary art (Barnard, 2019).

Each time period, contributing to the formation of a certain picture of the world among dance directors, facilitates the emergence of their individual interpretation of national choreography. Simultaneously, it gives an impetus to significant changes that affect both the national dance language development and the formation of new art forms.

In the initial periods of its formation, Kazakh choreography was influenced by the dominant artistic direction of the totalitarian Soviet state, called "socialist realism". As a result, the main attention of dance directors and choreographers of that time was paid to the presentation of the values developed by the Soviet ideology. Having gained independence, Kazakhstan focused all its efforts on the strengthening of the young state. Only by the middle of the first decade of the 2000s, the choreographers renewed the application of traditional dancing elements, thereby actively developing innovative dance techniques. This fact led to the emergence of novel director's interpretations of traditional Kazakh choreography (Zhanibek et al., 2020). After Kazakhstan gained independence, its theater and dance culture began to open up to trends and styles that were previously completely inaccessible. Among them are influences from, for example, the modern techno dance of South Korea, popular all over the world (Saitova et al., 2016).

The amalgamation of classical and folk material is a process where the national ideas are expressed by means of classical dance (Cross et al., 2014). Accordingly, the performance of the national as classical is "stylization", and the level of their unity and integrity is "synthesis" (Moldakhmetova \& Saitova, 2020). This definition is also applicable to the combination of national and modern dancing styles. Some researchers relying on Western terminology and interpretation experience call this phenomenon "integration", since in the modern Kazakh dance an integral structure of traditional and classical ballet physical movement and conceptual fusion were created at the same time.

The manifestation of this "synthesis" can be vividly noted in the adagio Kerbugi and Barshagul in the ballet Aksak Kulan choreographed by Tleubayev to the music of Serkebayev, in the ballet Kyz-Zhibek (established in 2013) choreographed by Bulat Ayukhanov to the music of Yevgeny Brusilovsky, and dance performance Syi-Siyapat by Tati. They express the combination of classical legs' movements and academic positions of hands of Kazakh dance with a "wring". The example of stylization in Kazakh choreographic art is the ballet Frescoes by Raibayev and dance numbers Revived Petroglyph (established in 2017) and Kosbasar (established in 2017) by Sadykova. They express the spirit of the archaic period in the modern 
context, representing the fusion of two phenomena - the old and the new, "foreign" and "native". This dichotomy is equally characteristic of the history of choreography in European national dance schools (Tleubayev et al., 2019).

If the director's stylisation technique as a dialogue, then its communicative orientation in accordance with the modern cultural context comes to the fore. Using the example of the ballet Frescoes, one can note that Raibayev turned to the ancient era of the Kazakhs in order to familiarize the Kazakh people with their historical traditions. This dialogue between the choreographer and society represents aspirations for the revival and growth of national identity. Without a doubt, the preservation of the authenticity of the nationality in the director's interpretations through dance vocabulary is an important aspect. Staging and writing activities require thoughtful research work from the director, particularly in studying the semantic meanings of dance vocabulary. It is not always possible to follow the strict meaning of each dance movement (Powell, 2019). Nevertheless, the director needs to be guided by a similar dance vocabulary, so that the meanings contained in each movement make up a phrase or a whole fragment, the content of which would be easy to understand. This is an important criterion in the presentation of national choreographic work because the world of semantic convergence, analogies, and oppositions, which does not coincide with the semantic grid of the natural language of choreography, comes into conflict with it (Tleubayev, 2000). A specific approach to dance segmentation into related fragments has been effectively used for three-dimensional dance modeling and now forms the basis for interactive accompaniment of choreography training and in online dance training systems (de Boer et al., 2018).

This study on the director's interpretation of the Kazakh dance, both in ballet performances and in theatre dances, is aimed at presenting the visual trace of the creativity of directors who have devoted much time to the development of choreography (Zhanibek et al., 2020). The significance of this research is in the possibility of determining the Kazakh choreography development trajectories in the perspective of creativity within the long time period. Besides, this article reveals certain axiological guidelines of the national choreography's future development in the context of modern creative processes.

The development of the Kazakh dance began in the 1930s (Tleubayev et al., 2019). Review of numerous scientific sources revealed a number of shortcomings in the director's interpretations (Robinson, 1990), among which the replacement of traditional dance with pantomime, which often captivates the viewer with sharp moments and lively expressiveness of talented actors (Bleeker, 2017; Sarynova, 1976); ignorance of the national specifics of Kazakh dance; and tendency towards thoughtless duplication of the national character expression manner, which reduces the importance of Kazakh dance art. Unlike the dance art of peoples, who for various reasons were in the center of attention of Western European and American choreographers and researchers, Kazakhs for almost the entire time of the existence of Kazakh dance were in the sphere of influence and interest of almost only the Russian cultural tradition (Kulbekova et al., 2019; Kussanova et al., 2020). Studies by art historians show that the formation of the Kazakh professional stage dance began in the 1930s-1940s of the 20th century, and from that moment the tradition of integration of folk tradition and ballet classics was formed (Moldakhmetova et al., 2018). Only in the 20th century the process of actively attracting trends from the Western choreographic tradition and modernity began, and the presentation of the Kazakh dance tradition to the West (Moldakhmetova et al., 2018). 
Several decades ago, due to the lack of a particular trajectory for the study of Kazakh dance in the perspective of creativity, the expression of traditional culture (beliefs, customs, rituals, education) was not the main purpose of creating a national dance performance. Notwithstanding this, it should be noted that variably successful attempts in creating national dance shows led to the search for new ways of creation and expression of Kazakh culture images (Shankibayeva, 2011).

\section{Conclusions}

The analysis of the compositions shows that the directors not only took ready-made samples from other arts or history and copied them, but also presented their own interpretation, based on their own creativity and creating something radically new, original and non-stereotypical.

Based on the analysis of a number of dance performances, the conclusion can be made that the last quarter of the 20th century, defined by the period of ethnic renaissance in the work of Kazakh directors-choreographers, was of great importance both in the development of the country's choreography. The analysis of the study show the dominance of creativity in the works of all directors that mean their appeal on the connection of the ancient tradition and original creativity. An authentic Kazakh dance, based on the appeal to the early periods of Kazakh ethnogenesis, demonstrates the aspiring desires of choreographers to revive cultural heritage and update it with the help of creativity.

Therefore modern dance directors strive to follow the values laid down by their prior fellows, at the same time they develop their understanding of choreography, which allows them to look at dance more broadly in accordance with the possibilities of creativity, created on the basis of originality, relevance and non-stereotyping.

The study represents the fact according to which today's interpretations of choreography differ from the previous experience. The tendency to express the inner state of a person noted in the dances of the beginning of the 21st century reflects the development of new trends based on the expression of creative ideas through the difficult movements in the choreographic art. Appealing to mythology, Kazakh ballet masters direct the modern viewer's attention to the psychoanalysis of spirituality. Modern dance also differs from previous by the actualization of the creativity on all stages of dance creation and functioning.

The analysis of common and distinctive features of the director's interpretation of Kazakh dance allows rethinking the attitude of young directors-choreographers towards the Kazakh choreographic heritage. In addition, it promotes the understanding of the further trajectory of choreography development in the perspective of creativity, where important aspects are the restoration of the prominent examples of national ballet and the introduction of specialized courses in the process of training future directors-choreographers.

\section{References}

Banban, D. (2018). Harmony in diversity: An empirical study of harmonious co-existence in the multiethnic culture of Qinghai. International Journal of Anthropology and Ethnology, 2(1).

https://doi.org/10.1186/s41257-018-0010-6 
Barnard, A. (2019). Culture: The indigenous account. In M. Ch. Behera (Ed.), Shifting perspectives in tribal studies: From an antropological approach to interdisciplinarity and consilience (pp. 37-51). Springer Nature Singapore Pte Ltd. https://doi.org/10.1007/978-981-13-8090-7_2

Bleeker, M. (Ed.). (2017). Transmission in motion: The technologizing of dance. Routledge.

Boer, de V., Jansen, J., Tjon-A-Pauw, A.-L., \& Nack, F. (2018). Interactive dance choreography assistance. In A. D. Cheok, M. Inami, \& T. Romão (Eds.), Lecture notes in computer science: Vol. 10714. Advances in Computer Entertainment Technology, ACE 2017 (pp. 637-652). London, UK. Springer International Publishing AG. https://doi.org/10.1007/978-3-319-76270-8_45

Carey, K., Moran, A., \& Rooney, B. (2019). Learning choreography: An investigation of motor imagery, attentional effort, and expertise in modern dance. Frontiers in Psychology, 10. https://doi.org/10.3389/fpsyg.2019.00422

Carter, C. (2020). Dance and choreography as a method of inquiry. Forum: Qualitative Social Research, 21(3). https://www.qualitative-research.net/index.php/fqs/article/view/3448/4639

Chappell, K. A., \& Hathaway, C. (2018). Creativity and dance education research. In P. Thomson (Ed.), Oxford research encyclopedia of education (pp. 1-47). Oxford University Press. https://doi.org/10.1093/acrefore/9780190264093.013.386

Clements, L., \& Redding, E. (2020). Creativity in higher education contemporary dance: An interpretative phenomenological analysis. Journal of Dance Education, 20(2), 88-98. https://doi.org/10.1080/15290824.2019.1572155

Coulson-Thomas, C. (2017). Stimulating creativity, enabling innovation and supporting entrepreneurship. Management Services (Summer Iss.), 26-29.

Cross, E. S., Acquah, D., \& Ramsey, R. (2014). A review and critical analysis of how cognitive neuroscientific investigations using dance can contribute to sport psychology. International Review of Sport and Exercise Psychology, 7(1), 42-71. https://doi.org/10.1080/1750984X.2013.862564

Georgios, L. (2018). The transformation of traditional dance from its first to its second existence: the effectiveness of music-movement education and creative dance in the preservation of our cultural heritage. Journal of Education and Training Studies, 6(1), 104-112. https://doi.org/10.11114/jets.v6i1.2879

Guss-West, C., \& Wulf, G. (2016). Attentional focus in classical ballet: A survey of professional dancers. Journal of Dance Medicine and Science, 20(1), 23-29. https://doi.org/10.12678/1089-313X.20.1.23

Hanakawa, T. (2016). Organising motor imageries. Neuroscience Research, 104, 56-63. https://doi.org/10.1016/j.neures.2015.11.003

Karp, P. (1980). Balet i drama. Iskusstvo.

Kasirer, A., \& Shnitzer-Meirovich, Sh. (2021). The perception of creativity and creative abilities among general education and special education teachers. Thinking Skills and Creativity, 40. https://doi.org/10.1016/j.tsc.2021.100820

Kulbekova, A., Tleubayev, S., Bakirova, G., Kabdusova, D., Tleubayeva, B., \& Mambetova, G. (2019). Kazakh national culture and ceremonies as a philosophy of ethnic identity. Opción: Revista de Ciencias Humanas y Sociales, 35(90-2), 67-85.

Kussanova, A. E., Kulbekova, A. K., Tleubayeva, B. S., \& Nikolayeva, L. A. (2020). Stylistic features and development trends of choreographic stage direction in Kazakhstan. Opción: Revista de Ciencias Humanas y Sociales, 36(91), 58-71.

Łucznik, K., \& May, J. (2021). Measuring individual and group flow in collaborative improvisational dance. Thinking Skills and Creativity, 40. https://doi.org/10.1016/j.tsc.2021.100847

Ma, R. (2007). A new perspective in guiding ethnic relations in the Twenty-First century: "De-Politicization" of ethnicity in China. Asian Ethnicity, 8(3), 199-217.

https://doi.org/10.1080/14631360701594950 
Malloch, S., \& Trevarthen, C. (2018). The human nature of music. Frontiers in Psychology, 9. https://doi.org/10.3389/fpsyg.2018.01680

Moldakhmetova, A. T., \& Saitova, G. Y. (2020). The concept of "Choreographic Integrity" in the methods of national dance stylization. News of the National Academy of Sciences of the Republic of Kazakhstan: Social and Human Sciences, 1(329), 128-135. https://doi.org/10.32014/2020.2224-5294.14

Moldakhmetova, A. T., Zhumaseitova, G. T., Kim, L. V., Saitova, G. Y., \& Kenzikeev, R. V. (2018). Dance movements of Baksy as a paradigm of development of the Kazakh dance art. Rupkatha Journal on Interdisciplinary Studies in Humanities, 10(3), 38-57. https://doi.org/10.21659/rupkatha.v10n3.05

Mukhambetova, A. I. (2003). Ocherki istorii iskusstv Kazakhstana. Oner.

Nasev, L. (2013). Integrating music and dance into school curriculum. Activities in Physical Education and Sport, 3(1), 95-97.

Pavlik, K., \& Nordin-Bates, S. (2016). Imagery in dance: A literature review. Journal of Dance Medicine and Science, 20(2), 51-63. https://doi.org/10.12678/1089-313X.20.2.51

Powell, H. E. (2019). Modern dance choreography: Beyond the movement; an analysis between lyrics and movement. Can identities be developed through modern dance choreography? Annual Review of Education, Communication and Language Sciences, 16(2), 65-107.

Robinson, J. (1990). L'aventure de la danse moderne en France (1920-1970). Éditions Bougé.

Rudd, J., Buszard, T., Spittle, Sh., O’Callaghan, L., \& Oppici, L. (2021). Comparing the Efficacy (RCT) of learning a dance choreography and practicing creative dance on improving executive functions and motor competence in 6-7 years old children. Psychology of Sport and Exercise, 53. https://doi.org/10.1016/j.psychsport.2020.101846

Saitova, G. Y., Tskhay, A. S., \& Kenzikeyev, R. V. (2016). Korean stage dance as a new trend in Kazakhstan choreography. Global Media Journal, 14(26), 1-11.

Sarynova, L. P. (1976). Baletnoe iskusstvo Kazakhstana. Nauka.

Shankibayeva, A. (2011). Kazakhskaya khoreografiya: razvitiye form i khudozhestvennykh sredstv. Zhurgenov Kazakh National Academy of Art.

Shumilova, E. I. (1974). Natsional'nyye aspekty $v$ sovetskom balete. V muzyke i khoreografii sovremennogo baleta. Muzyka.

Stinson, S. W. (2006). Research as choreography. Research in Dance Education, 7(2), 201-209. https://doi.org/10.1080/14647890601029618

Sytova, E. V. (2001). Khoreograficheskoye iskusstvo i deti: esteticheskiye i nravstvennyye aspekty vospitaniya. Yaroslavl State Pedagogical University named after K. D. Ushinsky. Yaroslavl, Russia [unpublished source].

Tleubayev, M. (2000). Zametki o baletnoy postanovke Aksak Kulan. Razmyshleniya i kommentarii. Rukopis.

Tleubayev, S. Sh., Kulbekova, A. K., Tleubayeva, B. S., Saparova, Y. A., Kabdusova, D. Y., Dildebaeva, G. R., \& Isengaliyeva, A. G. (2019). The ethnogenesis of the Kazakh dance. Opción: Revista de Ciencias Humanas y Sociales, 34(87-2). https://produccioncientificaluz.org/index.php/opcion/ article/view/30424/31474

Wang, X., \& Zhang, Ch. (2018, 10-11 November). Connotation interpretation on modern value of national dance. In J. Li \& Sh. Song (Eds.), Advances in social science, education and humanities research: Vol. 264. Proceedings of the 2018 5th International Conference on Education, Management, Arts, Economics and Social Science (ICEMAESS 2018) (pp. 1154-1158). Sanya, China. Atlantis Press. https://doi.org/10.2991/icemaess-18.2018.229

Zhanibek, K., Toigan, I., Samal, B., \& Saitova, G. (2020). The role of folklore and various types of art in the development of Kazakh dance. Journal of Talent Development and Excellence, 12(1).

https://www.iratde.com/index.php/jtde/article/view/1163 